\title{
An evaluation of train control information systems for sustainable railway using the analytic hierarchy process (AHP) model
}

\author{
${\text { Evelin } \operatorname{Krmac}^{1} \text { (D) Boban Djordjević }}^{1}$
}

Received: 10 January 2017 / Accepted: 19 June 2017 / Published online: 30 June 2017

(C) The Author(s) 2017. This article is an open access publication

\begin{abstract}
Purpose In the process of nowadays efficiency evaluation of any mode of transportation, sustainability results are the most important factor. In regard to railway sustainability, Train Control Information Systems (TCIS) are such advanced systems with important positive impacts. The main purpose of this study was therefore the evaluation of these impacts as well as the evaluation of Key Performance Themes (KPT) for sustainable railways.

Methods Firstly a very detailed literature review of papers that have focused on TCIS and their improvements on railway sustainability, published in the scientific journal in the period from 2005 and 2016, was performed. The number of studies was then used as a main criteria in Analytical Hierarchical Process (AHP) evaluations or rankings of these systems and their impacts.

Results The paper offers results from the first systematic review of papers which investigate the role of TCIS in terms of sustainability and, additionally, represents a refined approach to TCIS classification with a new classes descriptions. During review KPT for sustainable railways were also identified. Further, AHP evaluated the Train Management and Interlocking Systems and their subsystems as the most important TCIS, and safety and costs of equipment, installation, maintenance and operation as the most important themes.
\end{abstract}

Evelin Krmac

evelin.krmac@fpp.uni-lj.si

Boban Djordjević

bbn.djordjevic@gmail.com

1 Faculty of Maritime Studies and Transport, University of Ljubljana, Pot pomorscakov 4, SI-6320 Portoroz, Slovenia
Conclusions The results are important for both, scholars for their future research and for other railway stakeholders and decision makers, who must select different systems and technologies for implementation in their railway systems with emphasis on increasing performance and sustainability. The study offers also the opportunities for further research in regard to railway sustainability.

Keywords Information and communication technology • ICT $\cdot$ Train control information system $\cdot$ Railway sustainability $\cdot$ Key performance themes $\cdot$ KPT

$\begin{array}{ll}\text { Abbreviations } \\ \text { AHP } & \text { Analytical Hierarchical Process } \\ \text { In-CTA } & \text { In-Cab Train Advisory } \\ \text { ATC } & \text { Automatic Train Control } \\ \text { ICT } & \text { Information and Communication Technologies } \\ \text { ATO } & \text { Automatic Train Operation } \\ \text { ITS } & \text { Intelligent Transportation System } \\ \text { ATP } & \text { Automatic Train Protection } \\ \text { IXL } & \text { Interlocking System } \\ \text { ATS } & \text { Automatic Train Supervision } \\ \text { KPT } & \text { Key Performance Themes } \\ \text { CATO } & \text { Computer Aided Train Operation } \\ \text { MCDM } & \text { Multi-Criteria Decision Making } \\ \text { CR } & \text { Consistency Ratio } \\ \text { PTCS } & \text { Positive Train Control System } \\ \text { CTCS } & \text { Chinese Train Control System } \\ \text { RBC } & \text { Radio Block Centre } \\ \text { DAS } & \text { Driver Advisory Systems } \\ \text { SD } & \text { Science Direct } \\ \text { ERTMS } & \text { European Railway Traffic Management Systems } \\ \text { TCIS } & \text { Train Control Information System } \\ \text { ETCS } & \text { European Train Control System }\end{array}$


TMS Traffic Management System

GSM-R Global System for Mobile CommunicationsRailway

\section{Introduction}

For decades the global community has been concerned with the impact that transportation has on climate change, energy use and the environment. Additionally, limited financial resources for transport infrastructure require new and different approaches to constructing, planning, operating, and maintaining modes of transport [23]. Sustainability is therefore very important in the design of transportation solutions and infrastructure. However, there is still no standard definition and no standard way of considering transportation sustainability. Consequently, the progress towards transportation sustainability has to take place on at least three levels of sustainability: economic development, environmental protection, and social development and well-being [64].

In terms of sustainability, it is evident that rail transportation has considerable advantages compared to those of other modes of transport, such as road and air transport. This is true particularly because it has the lowest negative impact on environment and society [140]. Given this, the role of the railway in transportation systems was emphasized by the EC [37], resulting in various European Union Directives for the improvement of the primarily railway infrastructure components, services, safety, and interoperability [27-29]. Moreover, visions and goals of many railway systems, groups, and researchers are focused on further development of sustainable railways [33] and [100].

According to Fan et al. [38] and Franklin et al. [45] and many other researchers, the use or application of advanced Information and Communication Technologies (ICT), especially in conjunction with electronic technologies, together known as Intelligent Transportation Systems (ITS), has many different positive impacts on railway transport. Further, Chowdhury [24] stated that benefits, such as safety, mobility, efficiency, productivity, energy and the environment, and customer satisfaction "in already deployed ITS applications are becoming readily apparent", and highlighted the importance of the constant evolvement of ITS to "meet the needs of transport sustainability which is an essential part of any society's economy, environment, and progression". ITS as a set of technologies "share the characteristics with systems of systems for improving performance" [39] and represents "a synergy of systems for improving performance" [69].

In terms of railways, Train Control Information Systems (TCIS) are a complex of systems [39]. Indeed, they are composed of a large number of various kinds of components (mechanical, electrical, computer, etc.) with different types of interactions (local, simultaneous, etc.), which are interconnected and operate in synergy with each other. As for rail transportation, Franklin et al. [45] categorized rail ITS as the union of "Traffic Management Systems, Traveler Information Systems and E-ticketing Systems", where Traffic Management Systems include Rail Networks, Interlocking Systems in railway stations and Traffic Management Systems on trucks (outside of railway stations), known also as European Railway Traffic Management Systems (ERTMS). The ERTMS represents a unified Traffic Management System developed as a standard signalling system for European railways in order to harmonize TCIS. According to Goverde et al. [51], a Railway Safety System (as a kind of TMS) can be further divided into (i) Interlocking Systems within the station, (ii) Automatic Train Protection (ATP) systems as systems for fall-back to driver errors, (iii) Signalling Systems for open track, and (iv) trackfree detection devices such as track circuits and axle counters.

Given that the number of different ICT and ITS (i.e. advanced) technologies used in railway systems is too large to deal with in the same paper, and considering that the TCIS are one of the most important of their subsets, having significant impact on railway transportation sustainability, we decided to focus only on these systems. For this purpose, we started with a thorough literature review of scientific papers in which TCIS and their components or subsystems were studied. Further, we made a classification of TCIS and grouped them into four classes. The basis for this classification was that provided by [39], where TCIS are defined as a synergy of four components, namely "Interlocking Systems (IXL), Traffic Management Systems (TMS), Automatic Train Control (ATC) systems and Automatic Train Supervision (ATS) systems". We made an alteration in this method of classification, adding one new class, the In-Cab Train Advisory Systems, reorganized the content of some classes, and extended the description of each class and their subsystems.

During the review special attention was devoted to those papers that highlighted improvements provided by the application of TCIS and their components in railway systems. Since the TCIS could have significant impacts on different issues of railway performance, we also identified the issues as key performance themes (KPT) for sustainable railway and classified them in terms of sustainability. Furthermore, reviewed papers (i.e., their number) were used as a basis for evaluation of the importance of TCIS and their components (i.e., ranking of technologies), and for evaluation of the importance of the improvements of sustainability issues (ranking of the KPTs). The evaluations - i.e., - rankings were performed using the Analytical Hierarchical Process (AHP) method.

The contributions of this paper are several. It is the first systematic review paper which investigates the role of TCIS in terms of sustainability and, additionally, represents a refined approach to TCIS and subsystems classification, as well as being an extended and detailed description of classes. Secondly, the AHP method for evaluation of TCIS and for evaluation of KPT for sustainable railways, as well as the 
combination of systematic review and AHP as in this paper, to the best knowledge of the authors, have not yet been used. Indeed, according to the systematic review of Multi-Criteria Decision Making (MCDM) techniques [86], the AHP method was until now (precisely from 1993 to 2015) used only two times for evaluations in the field of railway traffic or railway transportation. In both cases it was used for other purposes than that in this paper: Mandic et al. [83] proposed an improvement of the two-phase multicriteria model in Serbian railways, and Gercek et al. [49] used AHP for an assessment of the rail transit networks. Ultimately, the approach we used for criteria selection for the calculation of relative importance weights in AHP process could also be considered unique. Usually judgments are subjective and rely on expert's opinions, surveys, etc.; but in our case, criteria were represented by the number of references.

We expect that the findings of this study will make a significant contribution to the research community in general, especially to the railway system community, which implies both decision makers and stakeholders. Regarding research community, our approach to extend traditional and systematic literature review using AHP could be simply reused in any other research. Further, the proposed approach provides overview of the trends in terms of research in the topic of the paper. The results of the research provide a good basis for further investigation of TCIS classes regarding KPT. Identification of importance of TCIS and their subsystems through KPT could be useful for policy makers when considering "points" affecting the specific KPT when implementing new or upgrading extant systems. For example, since the construction of the new railway tracks is expensive, it could be useful to know that the implementation of ERTMS could improve capacity (by removing bottlenecks) [12, 34, 51, $71,84,114,128,131]$, interoperability $[12,34,45,50,51,71$, $85,110,131]$, safety $[6,11,12,19,44,50,51,55,71,75,79,84$, $85,114,125,128,131]$, energy efficiency [ $34,84,114,131]$, and efficiency of operation [12, 34, 84, 85, 128, 131]. Further, according to the authors' opinions, these findings can ensure recognition of interactions between KPT and particular classes of TCIS. From that point of view, for instance, it is clear that upgrading passively protected level crossings into actively protected ones can provide a significantly higher level of safety [72, 80, 122, 135, 136, 149].

The rest of this paper is structured as follows. The next section provides the research methodology and results. This is followed by a description of findings and a discussion. Finally, the last section provides conclusions, including limitations of the work as well as directions for future research.

\section{Research methodology and results}

The research for this study was conducted in three main steps: (i) systematic literature review, (ii) identification and classification process, and finally (iii) AHP evaluation process. The outputs of each step were the inputs of the next step.

The research therefore started with the rigorous and detailed systematic literature review of the scientific journal papers, primarily to obtain the answers to our research questions - which and how often individual TCIS and their subsystems were studied and what are the impacts of these TCIS systems and their subsystems on the sustainability of railways.

The next step in our research was a (re)definition of classes of TCIS and their subsystems, and of the set of KPT for sustainable railways. The basis (the input) for this step were results from the review, which were further studied and refined through our knowledge and prior research results.

The third step was dedicated to the two performances of the AHP method, where the number of references - i.e., reviewed papers - was used as the criteria for (i) evaluation of the importance of the classes of TCIS, and (ii) evaluation of the impacts of TCIS, denoted as KPT for sustainable railway.

At the very beginning of this study we hoped that we could find a relationship between classes of TCIS and individual KPT for sustainable railway and therefore be able to rank classes of TCIS according to the importance of their impacts on railway sustainability in terms of KPT, but this was not possible due to a lack of some data (essentially, we didn't have/couldn't obtain the same KPT for all classes of TCIS).

The complete research process is shown in Fig. 1 and described in details in following subsections.

\subsection{Systematic review methodology}

The main reason a systematic literature review has been used as a research strategy in this study lies in the fact that a systematic review is defined as "a rigorous, replicable, scientific and transparent process" [10], the main purpose of which is "to identify, present and discuss the most important contributions in a particular area of study" [8]. It also "aims at providing a classification, conducting a thematic analysis, or presenting publication channels" [108].

As shown in Fig. 2 the review process was performed in two steps, namely basic and supplementary search. Basic search started with the application of the initial search string (information railway technology OR communication railway technology AND train control system OR monitoring system OR signaling system OR warning system AND improvement OR benefit), resulted from research questions, using the two most important (and largest) scientific databases for actual thematic analyses, Science Direct and Scopus. The initial search in Science Direct (SD) resulted in a very large set of papers (7388). The search was performed using title, abstract and keywords. Considering the inclusion and exclusion criteria (see Fig. 2), in the next iteration of the search only English written full-text for free available scientific journal papers, published in the period from 2005 to 2016 (the search 
Fig. 1 Steps and results of the research process

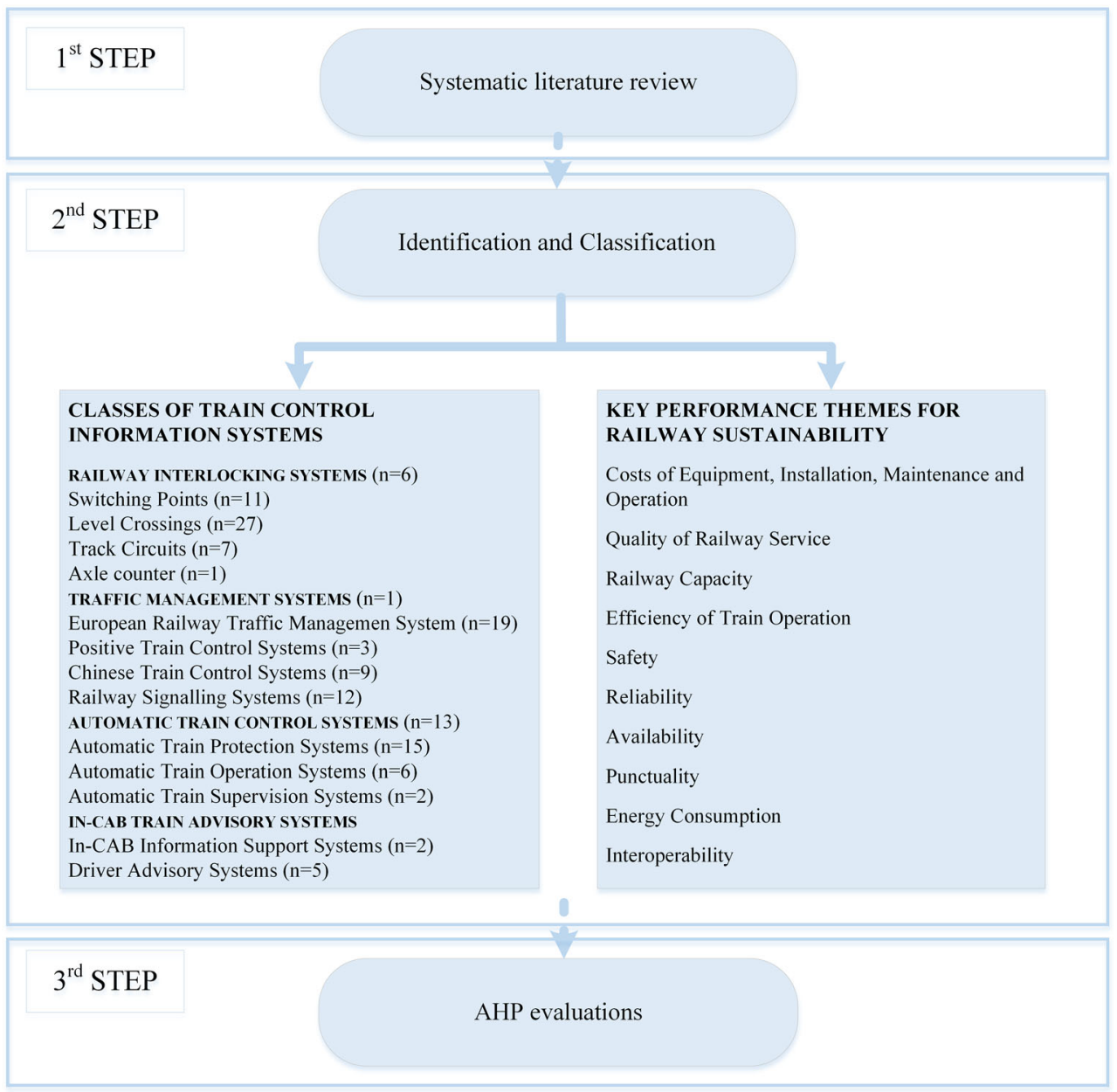

was finished in September 2016), were considered. Because the number of found papers was still very high (3056), the process continued with abstract reading after which only 269 papers remained in the process. Regarding the Scopus, the search process with the initial search string performed using article title, abstract, keywords resulted in 54 papers. After applying the same limitations as in SD, the number of papers was reduced to 5. All 274 papers were first subjected to fulltext reading, where compliance with inclusion criteria and goal of research were checked by both authors. The snowballing process entered all papers, that both of authors considered fully suitable for the research. During the snowballing process, titles and (only when appropriate, i.e. when inclusion criteria were met) abstracts of references of all selected papers were checked with the aim of verifying whether any other paper met the search criteria within the scope of research. During this step, we did not find any new paper added. The final set of papers found in the basic search step therefore numbered 66.

The basic search was therefore focused only on those papers that considered TCIS or their subsystems from a sustainability point of view, emphasizing the improvements and benefits of these systems. Actually, a lot of papers consider TCIS or particular classes, and some of them also some aspect(s) of sustainability, but a lot of them did not indicate the improvements or benefits for railways (at least not in their titles, abstracts or keywords), or they only described systems from technical aspects and technological development. In this context and in order to improve the initial, basic search, we performed a supplementary search process (the search was performed in March 2017), where in the partial search strings were firstly defined and then performed on both the Science Direct and Scopus databases. All details about search strings, the process itself and the numbers of found papers for each string and for each database are shown in Fig. 2.

The overall set of papers from the first and second step resulted in 129 papers. The list of the journals where these papers were published, is given in Table 1. All these papers then entered the identification and classification process.

\subsection{Identification and classification process}

The process aimed to (i) define and appropriately (re)describe the classes of TCIS and their subsystems, and (ii) to identify 


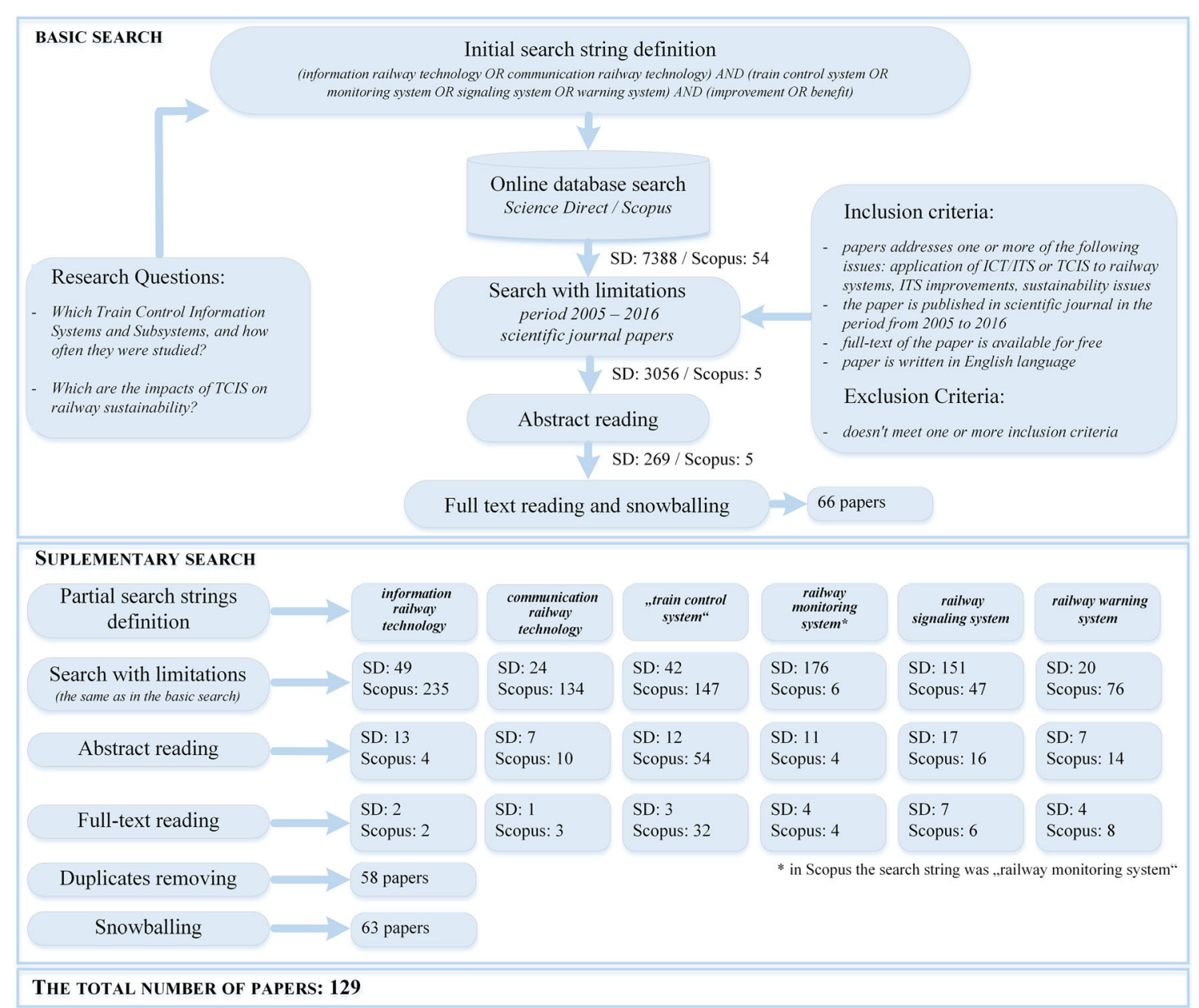

Fig. 2 The systematic literature review process

and select those KPT that are relevant for measuring the impacts of TCIS for railway sustainability, both according to the literature review outcomes.

\subsubsection{TCIS classes}

The description of TCIS classes, made by Fantechi et al. [39], was used as a starting point of our classification process because it fit well with our way of thinking on various points, starting from the assumption, that TCIS could in general be divided into a group of systems that are safety-oriented and those that are not. Further, they divided TCIS into four main classes, which are interconnected and operate in synergy with each other, namely Interlocking Systems (IXL), Traffic Management Systems (TMS), Automatic Train Control (ATC) Systems, and Automatic Train Supervision (ATS) Systems. The first important change we made to this classification is the inclusion of level crossings among railway IXL systems. The next one is the inclusion of ATS Systems in the ATC Systems class. After that a new fourth class was defined, In-Cab Train Advisory (InCTA) Systems, that embraces all non-safety systems. Finally, classes have been also appropriately (re)described.

\section{The description of TCIS classes and subsystems}

1. Railway Interlocking (IXL) Systems are a kind of TCIS used in railway stations to control the safety of train movements [67], defined as "an arrangement of signals and their appliances connected to follow each other according to the correct sequence" [150]. IXL includes train lines, separated on track segments, where each segment is connected to track circuits or axle counter [104] that detect, whether a particular segment is occupied by a train [18]. Switching points, as a special type of track segments, then allow the passage of the train from one train line to another [89], while positions of switches [88] control the connection of track segments [90]. Further, signals, placed between track segments, control permission of train movement from one track segment to another through displaying of different colours (red, yellow, green) that inform the train driver about the state of the following track segments [150]. The route represents a series of related track segments [65], most often through a set of switching points [141], with the possible existence of level crossings [13]. 
Table 1 Publication sources of identified papers

\begin{tabular}{|c|c|}
\hline Journal name & References \\
\hline Accident Analysis and Prevention & {$[72,101,122,135-137,147,153]$} \\
\hline Advances in Mechanical Engineering & {$[157]$} \\
\hline Applied Ergonomics & {$[113,117,124]$} \\
\hline Applied Mathematical Modelling & {$[67]$} \\
\hline Applied Soft Computing & {$[21]$} \\
\hline Computer Standards \& Interfaces & {$[19,74,115]$} \\
\hline Control Engineering Practice & {$[11,18,78,142,156]$} \\
\hline Electronic Notes in Theoretical Computer Science & {$[65,103,154]$} \\
\hline Energy Conversion and Management & [34] \\
\hline Engineering & [99] \\
\hline Engineering Applications of Artifical Intelligance & {$[15,16,32,104]$} \\
\hline Engineering Failure Analysis & {$[90]$} \\
\hline Engineering Structures & {$[97]$} \\
\hline European Journal of Operational Research & [89] \\
\hline IATSS Research & {$[70]$} \\
\hline IEEE Journal on Selected Areas in Communications & {$[160]$} \\
\hline IEEE Sensors Journal & [148] \\
\hline IEEE Transactions on Intelligent Transportation Systems & $\begin{array}{l}{[14,42,77,93,126,134,143,144,158} \\
\quad 159,162]\end{array}$ \\
\hline IEEE Transactions on Vechicular Technology & {$[161]$} \\
\hline IEEE Vehicular Technology Magazine & {$[81]$} \\
\hline IET Intelligent Transport Systems & {$[102]$} \\
\hline IFAC-PapersOnLine & {$[1,17,35,55,84,87]$} \\
\hline Indonesian Journal of Geography & {$[30]$} \\
\hline International Journal of Critical Infrastructure Protection & [6] \\
\hline International Journal of Systems Science & {$[92]$} \\
\hline Journal of King Saud University-Science & {$[54]$} \\
\hline Journal of Rail Transport Planning \& Management & {$[26,51,58,105,125,131,138]$} \\
\hline Journal of Systems and Software & {$[163]$} \\
\hline Journal of Transportation Safety \& Security & [94] \\
\hline $\begin{array}{l}\text { Journal of Transportation Systems Engineering and Information } \\
\text { Technology }\end{array}$ & {$[52,155]$} \\
\hline Mathematics and Computers in Simulation & {$[150]$} \\
\hline Microprocessors and Microsystems & {$[66]$} \\
\hline Neurocomputing & {$[80,107,127]$} \\
\hline Procedia Computer Science & {$[112,141]$} \\
\hline Procedia Manufacturing & {$[123]$} \\
\hline Procedia Technology & [7] \\
\hline Procedia-Social and Behavioral Sciences & [85] \\
\hline $\begin{array}{l}\text { Proceedings of the Institution of Mechanical Engineers Part F: Rail } \\
\text { and Rapid Transit }\end{array}$ & {$[106,129]$} \\
\hline Quarterly Report of the Railway Technical Research Institute & {$[3,46,47,56,60-62,68]$} \\
\hline Reliability Engineering and System Safety & {$[9,22,48,75,79,88,130]$} \\
\hline Research in Transportation Business \& Management & [71] \\
\hline Safety Science & {$[44,59,145,149]$} \\
\hline Science of Computer Programming & {$[41,43,63]$} \\
\hline Simulation Modelling Practice and Theory & {$[110,111]$} \\
\hline Systems Engineering Procedia & {$[57]$} \\
\hline Transportation Research Part B & [98] \\
\hline Transportation Research Part C & {$[4,12,25,50,76,146,152]$} \\
\hline Transportation Research Part E & {$[91]$} \\
\hline
\end{tabular}


Table 1 (continued)

\begin{tabular}{ll}
\hline Journal name & References \\
\hline Transportation Research Part F & {$[73]$} \\
Transportation Research Procedia & {$[128]$} \\
Vehicle System Dynamics & {$[2]$} \\
WIT Transactions on The Built Environment & {$[36,95,96,114,116,133,151]$} \\
\hline
\end{tabular}

2. Traffic Management Systems (TMS) provide movement authority to the trains with a guaranteed increased level of safety and capacity utilization. All signalling systems continuously communicate with the interlocking systems in order to get the information about track circuits or axle counter and route status [39].

The ERTMS signalling system is an example of the unified TMS for Europe. Based on the benefits claimed in the reviewed papers, it was designed to (i) enable interoperability through the use of one uniform European system $[12,34,45,50,51,71,85,110,131]$; (ii) enhance traffic management and quality $[12,34,71,84,85,128$, 131]; (iii) optimize the usage of energy and network resources [34, 84, 114, 131]; (iv) increase capacity [12, 34, $51,71,84,114,128,131]$, and (v) increase safety within the railway sector $[6,11,12,19,44,50,51,55,71,75,79$, $84,85,114,125,128,131]$. The ERTMS is composed of two large subsystems: the first is the European Train Control System (ETCS), which has replaced national Automatic Train Protection (ATP) systems [51], and is implemented as an on-board part and as a part of fixed infrastructure. The second subsystem is the Global System for Mobile Communications-Railway (GSM-R) [6], which is a communication system that allows continuous communication between the ETCS on-board part and the ETCS trackside parts through EURORADIO [19, 20].

The ERTMS was introduced as a standard in order to replace and harmonize national railway control and signalling systems, which vary greatly from country to country [25]. There are three ETCS levels. Level 1 represents track to train communication, provided by Eurobalises located along tracks that interface with the existing signalling system and line side signals. Level 2 is an enhancement of Level 1 with movement authority from Radio Block Centre $(R B C)$ through interlocking to on-board ECTS via GSM-R link, which enables the elimination of trackside signals. Level 2 covers track-to-train communication and vice versa. On this level, $R B C$ calculates the correct movement authority, giving authorization to proceed (or not), with balises used to transmit static messages such as location, line profile, and speed limit. Further, Level 3 improves the ability of Level 2 so that train detection by the trackside is no longer required. At this level, the $R B C$ uses $G S M-R$ for transmission between track and train. Compared with Level 1 and 2 which are based on a fixed block signalling system, Level 3 allows a moving block signalling system; this means that as the train travels, the track receives the train location and train integrity from the train. Levels 1 and 2 are already widely applied in Europe, while Level 3 is currently under development $[11,110]$. The ERTMS has been adopted in countries such as South Korea, Taiwan, Turkey, Algeria, Argentina, and New Zealand.

Inspired by the ERTMS, China has developed an equivalent signalling and control system, called the Chinese Train Control System (CTCS) [50]. American railways on the other hand are in the process of introducing a wireless network-based control system, commonly referred to as a Positive Train Control System (PTCS) [7].

3. Automatic Train Control (ATC) Systems, composed of an on-board-trains part and trackside part, are intended to supervise and control the maximum train speed and automatically brake in case of need. In this way they improve the safety and adjust the train operations to guarantee punctuality (according to the schedule) and comfort [44, 76]. One example of automated train control is the communication-based train control system [160-162].

This class of systems include Automatic Train Protection (ATP), Automatic Train Operation (ATO) and Automatic Train Supervision (ATS) systems. ATP ensures the safety of movement of the trains and the consistent protection of the line traffic, stopping the train in case drivers fail to respect a signal $[9,43]$. ATO is used for observing the maximum and safe speed limits, and also for stopping the train at stations, where the intervention of human drivers is reduced to the starting up of the train after each stop (often at the metro stations) [15, 32]. ATS functions are crucial and represent a nerve centre especially in degraded situations, such as unavoidable incidents, where operators' intervention is required [9].

4. In-Cab Train Advisory (In-CTA) Systems represent a class of those systems that aim to provide the train driver with a variety of important information. These systems can be divided into two main groups: In-Cab Information Support Systems, which provide information for passengers, for maintenance purposes, and video monitoring of the inside of vehicles, and Driver Advisory Systems (DAS) [40]. The latter complements signalling systems in terms of traffic management improvement procuring permanent 
information to drivers about train times with respect to the published timetable in order to achieve higher levels of punctuality, improvement of energy efficiency and avoidance of conflicts with other trains [105, 138].

With In-CTA systems energy consumption could be reduced while providing a smoother ride to drivers by giving them speed recommendations and informing them about potential conflicts within railway systems that lead to unplanned stops, cause additional delays and higher energy consumption [1, 36, 105, 117, 138]. According to the results of the simulation presented in [1], DAS allow trains to reach $20 \%$ of energy saving in conflict situations in comparison to driving with the information received from signalling systems. Similar data i.e. possible savings with DAS of up to $28 \%$ has been highlighted in [34]. Based on the evaluations by Transrail, in [138] it has been pointed out that with DAS CATO (Computer Aided Train Operation) Swedish railways have shown possibilities for energy savings up to $25 \%$. However, the reduction of savings is possible because they significantly depend on users (so there are instances of misunderstanding or lack of knowledge about the device, misinterpretation or ignorance regarding the advice) [1, 34, 105]. Therefore, although some studies have shown that DAS make it possible to achieve savings below that predicted, it may be concluded that smart and efficient driving techniques and greater knowledge of devices have the potential to save a larger amount of energy [1, 34].

As the classes of systems and their subsystems were thereafter used as alternatives in the AHP evaluation process, their precise division into classes and their subclasses as well as related references for each of them, found during systematic review, are clearly shown in Fig. 3.

\subsubsection{KPT for sustainable railway classification}

Another valuable output from systematic review was the list of key performance themes that were used for evaluation of TCIS from the sustainability point of view. The KPT in the list were considered as a set of sub criteria for evaluation of the importance of each KPT regarding individual TCIS classes and their subsystems.

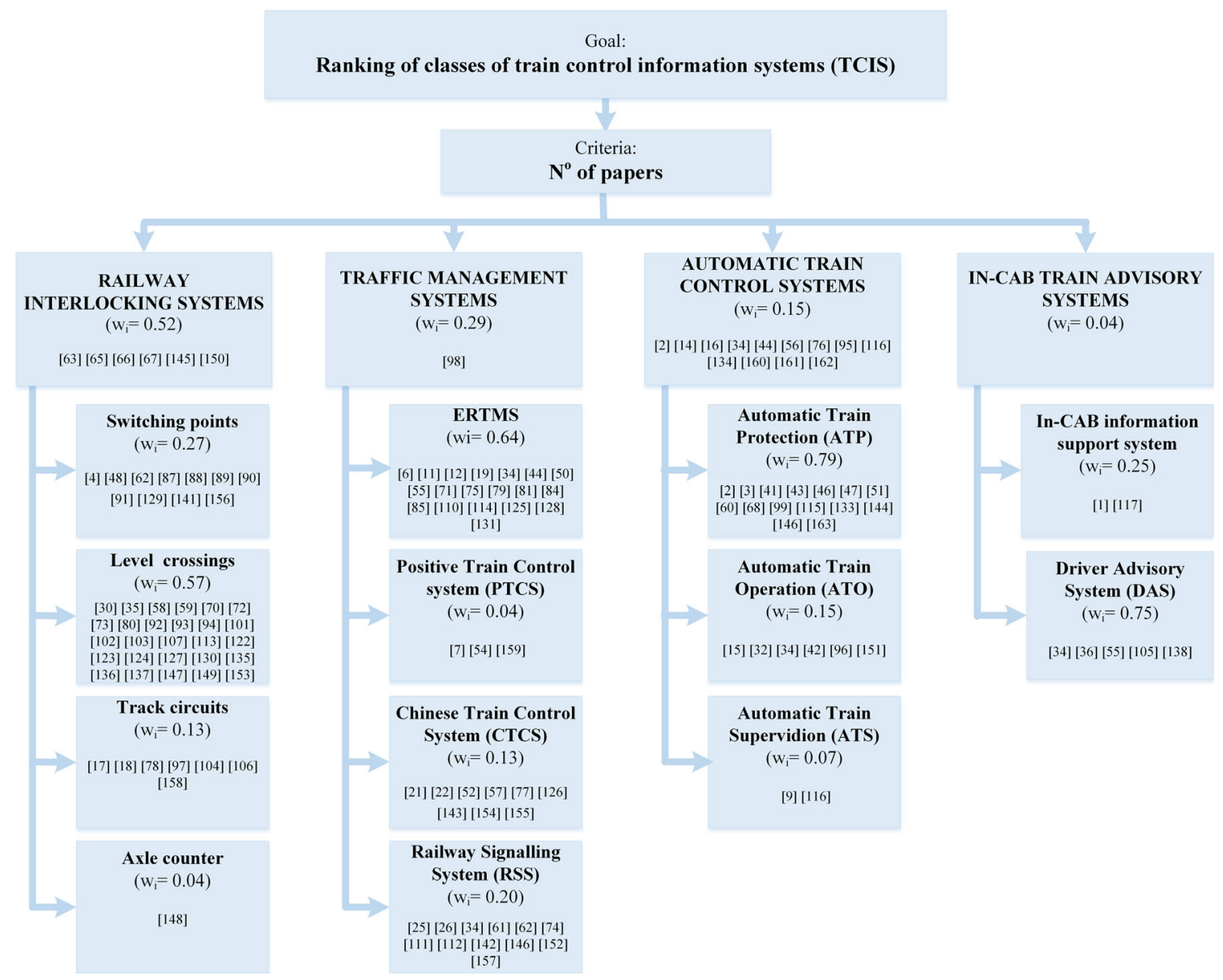

Fig. 3 AHP hierarchy for classes of TCIS ranking 
Key performance themes (KPT) could be related to appropriate sets of indicators used to report the progress towards delivery regarding factors identified as critical to the success of transportation organization's goals and objectives. As such, KPT can be helpful and play an important role in terms of monitoring and evaluation of sustainable development and sustainable transportation. In order to determine how TCIS contributions to our railway system are becoming more or less sustainable, measurement of impacts against related KPT is necessary. Therefore, to be more precise, measurement of railway sustainability actually refers to measuring the improvements regarding sustainable railway [31].

Individual KPT were classified under the three pillars or dimensions of sustainability, transport and economy, environmental, and social. Among the common KPT that describe improvements by TCIS found in the literature for the transport and economy dimension, are the following (see Fig. 4 and Table 2): railway capacity, which is related to better utilization of rail tracks and networks, and efficiency of train operation, as an essential indicator which is generally related to assets on and around the track, as well as trains and their associated functions. Since the efficiency of operation entails numerous costs, cost of equipment, installation, maintenance and operation, were found. Further, significant improvements from TCIS are expected to be related to quality of railway service. Moreover, interoperability as one of the important issues, particularly for the trans-European high speed rail system (network), was addressed in terms of technical standardization. Interoperability improvements are related to users, but more importantly they are relevant for increasing efficiency, improving rail usage and minimizing operating costs. Furthermore, railway TCIS play an important role in the improvement of the level of safety and punctuality, which are the main themes that refer to the social dimension of railway sustainability together with the level of train service reliability and availability, which could also be significantly increased by the implementation of TCIS (see Fig. 4 and Table 3). Finally, enhancements of railway TCIS could have a positive impact on issues such as energy efficiency, which is the core theme of the environmental dimension of sustainable railways. The detailed classification of identified KPT, grouped by dimensions of railway sustainability, related classes of TCIS and their subsystems, including references found during review, are summarized in Tables 2 and 3.

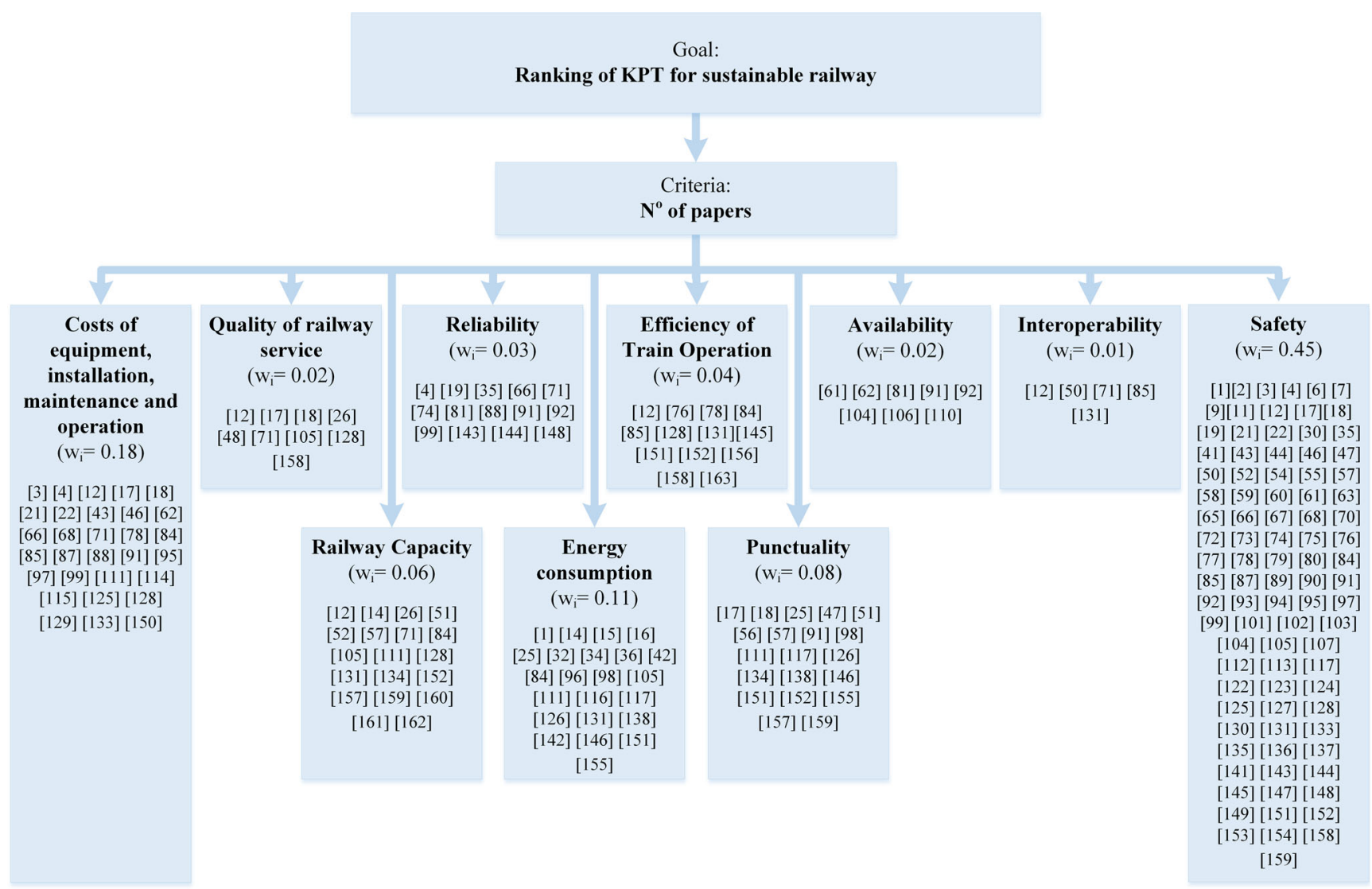

Fig. 4 AHP hierarchy for KPT for sustainable railway ranking 
Table 2 References for KPT's for each TCIS (economy and transport dimension)

\begin{tabular}{|c|c|c|c|c|c|}
\hline \multirow[b]{2}{*}{$\begin{array}{l}\text { KPT } \\
\text { TCIS }\end{array}$} & \multicolumn{5}{|l|}{ Economy and transport } \\
\hline & $\begin{array}{l}\text { Costs of equipment, } \\
\text { installation, maintenance } \\
\text { and operation }\end{array}$ & $\begin{array}{l}\text { Quality of } \\
\text { railway } \\
\text { service }\end{array}$ & $\begin{array}{l}\text { Railway } \\
\text { capacity }\end{array}$ & $\begin{array}{l}\text { Efficiency of train } \\
\text { operation }\end{array}$ & Interoperability \\
\hline Interlocking systems & {$[66,150]$} & & & [145] & \\
\hline Switching points & {$[4,62,87,88,91,129]$} & {$[48]$} & & {$[156]$} & \\
\hline Level crossings & {$[58,136,149]$} & & & & \\
\hline Track circuits & {$[17,18,78,97]$} & {$[17,18,158]$} & & {$[78,158]$} & \\
\hline \multicolumn{6}{|l|}{ Axle counter } \\
\hline \multicolumn{6}{|l|}{ Traffic Management Systems } \\
\hline ERTMS & $\begin{array}{l}{[12,71,84,85,114,125,} \\
128]\end{array}$ & {$[12,71,128]$} & $\begin{array}{l}{[12,71,84,128,} \\
\quad 131]\end{array}$ & $\begin{array}{l}{[12,84,85,128,} \\
\quad 131]\end{array}$ & $\begin{array}{l}{[12,50,71,85,} \\
131]\end{array}$ \\
\hline PTCS & & & [159] & & \\
\hline CTCS & {$[21,22]$} & & {$[52,57]$} & & \\
\hline RSS & [111] & {$[26]$} & {$[26,111,152,157]$} & {$[152]$} & \\
\hline Automatic train control systems & [95] & & {$[14,134,160-162]$} & [76] & \\
\hline ATP & {$[3,43,46,68,99,115,133]$} & & {$[51]$} & [163] & \\
\hline ATO & & & & {$[151]$} & \\
\hline \multicolumn{6}{|l|}{ ATS } \\
\hline \multicolumn{6}{|l|}{$\begin{array}{l}\text { In-cab information support } \\
\text { system }\end{array}$} \\
\hline DAS & & [105] & {$[105]$} & & \\
\hline
\end{tabular}

\subsection{Analytic hierarchical process (AHP) evaluation and ranking}

\subsubsection{About AHP}

The Analytic Hierarchical Process (AHP) approach is a common, very popular and widely used Multi-Criteria Decision Making (MCDM) method [139] aimed at "decomposing, organizing and analysing a complex problem" [82] and converting it into a hierarchical structure of various levels, such as goal, criteria, sub-criteria, and alternatives [118-120]. According to Harputlugil et al. [53] AHP is a better tool for solving the multi-criteria decision making problems in comparison to others (for example ELECTRE, DEMATEL, ISM, ANP, VIKOR and TOPSIS) because it is easy to use and a widely applicable and powerful tool for selection and evaluation purposes, both in engineering and social fields. Further, in the literature AHP has been used as a technique for identification priorities between factors, criteria or indicators in the purposes of selection and evaluation [5]. Moreover, it is applicable in decision making with various evaluation criteria under uncertain conditions.

AHP is based on a pair-wise comparison of the criteria or decision elements' importance with respect to the main goal to obtain their weights of importance, sometimes called also priorities or significances [121]. It helps decision makers to set priorities to alternatives with respect to each of the criteria, and to make the right decision. Thus, with AHP significances (relative weights) among criteria that are hierarchically nonstructured and vice versa in term of those belonging to a higher level are determined. The main advantages of the AHP method refer to the combination of qualitative and quantitative analysis, as well as the ability to capture both the subjective and objective aspects of a decision, helps control the consistency of measures, as well as reduce bias in decision making processes $[109,132]$.

The steps involved in the AHP process, are described below:

1. Formulation of the aim of the work and hierarchy construction: Decomposition of decision problem into individual items, taking into account their common characteristics, and formation of the appropriate hierarchical model with different levels (at least three: goal, criteria and alternatives).

2. Formation of the pair wise comparisons: Through pairwise comparisons between factors on one level compared with specific factors in the immediate upper level, local weights are calculated. In order to express a judgment about the significance of one factor relative to another, a nine point Saaty's scale (Table 4) is used.

3. Computation of the Eigen values, Eigen vectors and relative importance weights: Eigen values and Eigen vectors 
Table 3 References for KPT's for each TCIS (social and environment dimensions)

\begin{tabular}{|c|c|c|c|c|c|}
\hline \multirow[b]{2}{*}{$\begin{array}{l}\text { KPT } \\
\text { TCIS }\end{array}$} & \multicolumn{4}{|l|}{ Social } & \multirow{2}{*}{$\begin{array}{l}\text { Environment } \\
\text { Energy } \\
\text { consumption }\end{array}$} \\
\hline & Safety & Reliability & Availability & Punctuality & \\
\hline Interlocking systems & {$[63,65-67,145]$} & {$[66]$} & & & \\
\hline Switching points & {$[4,87,89-91,141]$} & {$[4,88,91]$} & {$[91]$} & [91] & \\
\hline Level crossings & $\begin{array}{l}{[30,35,58,59,70,72,73,80,92-94,101-103,107,113} \\
\quad 122-124,127,130,135-137,147,149,153]\end{array}$ & {$[35,92]$} & {$[92]$} & & \\
\hline Track circuits & {$[17,18,78,97,104,158]$} & & {$[104,106]$} & {$[17,18]$} & \\
\hline Axle counter & {$[148]$} & [148] & & & \\
\hline $\begin{array}{l}\text { Traffic Management } \\
\text { Systems }\end{array}$ & & & & [98] & [98] \\
\hline ERTMS & {$[6,11,12,19,44,50,55,75,79,84,85,125,128,131]$} & $\begin{array}{l}{[19,71} \\
81]\end{array}$ & {$[81,110]$} & & {$[34,84,131]$} \\
\hline PTCS & {$[7,54,159]$} & & & [159] & \\
\hline CTCS & {$[21,22,52,57,77,143,154]$} & [143] & & {$[57,126,155]$} & {$[126,155]$} \\
\hline RSS & {$[61,74,112,152]$} & {$[74]$} & {$[61,62]$} & $\begin{array}{l}{[25,111,146} \\
152,157]\end{array}$ & $\begin{array}{r}{[25,34,111} \\
142,146]\end{array}$ \\
\hline $\begin{array}{l}\text { Automatic train } \\
\text { control systems }\end{array}$ & {$[2,44,76,95]$} & & & {$[56,134]$} & $\begin{array}{l}{[14,16,34,} \\
116]\end{array}$ \\
\hline ATP & {$[2,3,41,43,46,47,60,68,99,133,144]$} & {$[99,144]$} & & {$[47,51,146]$} & {$[146]$} \\
\hline ATO & {$[151]$} & & & [151] & $\begin{array}{l}{[15,32,34,42,} \\
\quad 96,151]\end{array}$ \\
\hline ATS & [9] & & & & {$[116]$} \\
\hline $\begin{array}{l}\text { In-cab information } \\
\text { support system }\end{array}$ & {$[1,117]$} & & & {$[117]$} & {$[1,117]$} \\
\hline DAS & {$[55,105]$} & & & {$[138]$} & $\begin{array}{l}{[34,36,105} \\
138]\end{array}$ \\
\hline
\end{tabular}

are determined after pair-wise matrices are operated. As a result, the relative importance weights are calculated, where $\sum w_{i}=1$ should be for each pairwise comparison matrix.

4. Evaluation of the consistency ratio: To check for the consistency of the decision maker judgment, the consistency ratio $(\mathrm{CR})$ is computed:

$C R=\frac{\text { Consistency Index }(C I)}{\text { Random Inconsisteny }(R I)}=\frac{\text { Consistency Index }(C I)}{\text { Random Inconsisteny }(R I)} \frac{\text { Consistency Index }(C I)}{\text { Random Inconsisteny }(R I)}$, where $\lambda_{\max }$ is an Eigen value and $n$ is the number of criteria. The judgment results are consistent, if calculated value of CR results less than 0.10 .

Table 4 Scales in pair-wise comparisons

\begin{tabular}{ll}
\hline Score & Importance description \\
\hline 1 & Equally important. \\
3 & Moderately or weakly more important. \\
5 & Strongly important. \\
7 & Very strongly important. \\
9 & Extremely important. \\
$2,4,6$ and 8 & Intermediate values. \\
\hline
\end{tabular}

\subsubsection{AHP results}

As stated above, due to the ability of determination priorities, in this paper an AHP process was implemented for the purpose of evaluation and ranking of two things, firstly different classes of TCIS (with their particular subsystems), and secondly different KPT as impacts of TCIS for sustainable railway.

In order to build appropriate hierarchies, two goals, "Ranking the classes of TCIS" and "Ranking of KPT for sustainable railways" were defined. The criteria for both evaluations was the same, the number of reviewed papers in which a particular system or KPT was studied. Alternatives for the evaluation were therefore classes of TCIS and their subsystems on one side, and KPT as indicators of improvements of TCIS for sustainable railway on the other. Based on the number of references, the authors have determined judgements from the Saaty's scale in terms of the mutual dominance of elements for each level in a hierarchy. Pairwise matrices were created for each class of TCIS - i.e., for subsystems comparison and then one matrix was created for comparison of classes of TCIS. After that, for comparison of KPT another pairwise comparison matrix was created. Figure 5 presents the 
Fig. 5 Pairwise comparison matrix for TMS

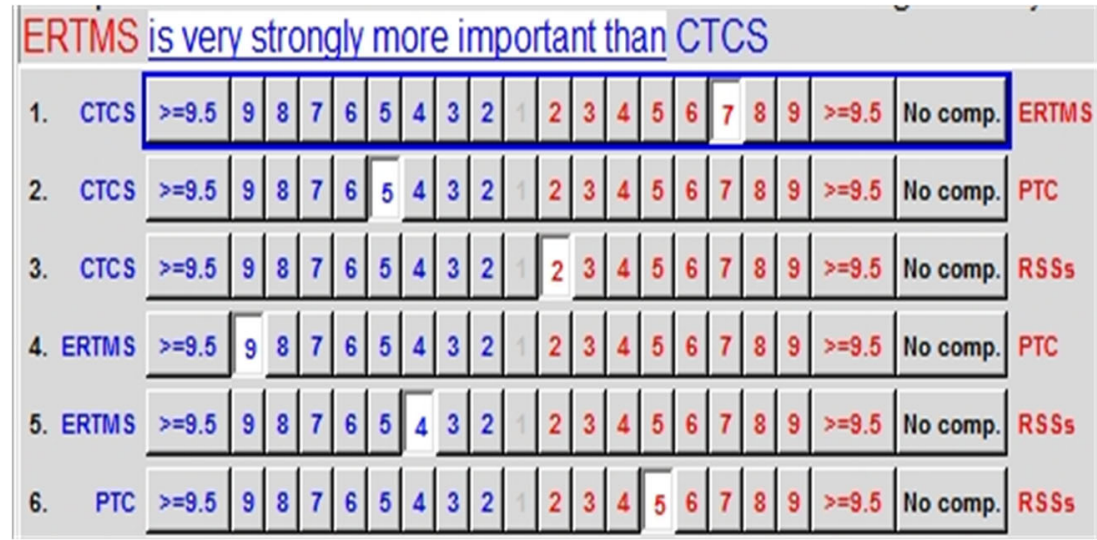

pairwise comparison matrix for TMS in "Super Decision" environment. The process was similar for each pairwise comparison matrix.

The relative importance weights were then calculated. The complete AHP hierarchies with computed relative weights and corresponding lists of references for TCIS classes and KPT for sustainable railways are given respectively in Figs. 3 and 4 . At the end of the AHP process, as the most important step of AHP, the consistency ratio (CR) was computed. The value of CR for the classes of TCIS was 0.09, while the value of CR for KPI for sustainable railway was 0.07 . In both cases the value of CR resulted in less than 0.10 , so was acceptable, and therefore both judgments were consistent.

The AHP process was performed using "Super Decisions" software (version 2.8.0), which is very suitable and capable of practical problem solving; furthermore it is also fully adapted for AHP and ANP (Analytical Network Process) decision making.

\section{Discussion of results}

The value of the importance for classes of TCIS and their subsystems represents the information regarding how much they were studied in the scientific literature. The results of the "Super Decisions" software (see Fig. 3) have shown that the Railway Interlocking Systems (IXL) and the Traffic Management System (TMS) are the most important classes of TCIS, followed by Automatic Train Control (ATC) systems and In-Cab Train Advisory (In-CTA) systems. Based on that, it could be said that the order of classes of TCIS imply their importance in the improvement and creation of sustainable railways. Since the IXL in interaction with TMS, which covers the whole railway network, are responsible for the betterment of more KPT, it is clear that they attracted more attention among scholars.

Furthermore, values for individual subsystems show, that within the Interlocking Systems the highest importance was given to level crossings, followed by switching points, train circuits, and axle counter. Among the Train Management Systems, the ERTMS has attracted the most attention (followed by the much lower ranked Railway Signalling Systems, CTCS and PTC, respectively) (see the results of the pairwise comparison matrix in Fig. 5). Further, ATP has the greatest importance within the Automatic Train Control Systems, followed by ATO and ATS. Finally, for In-Cab Train Advisory Systems, the Driver Advice Systems are more important than the In-cab Support Information system. Regarding the subsystems, findings indicate which of them within classes of TCIS play an important role for railways. As the level crossings represent "black points" for railways and road users, their upgrading can improve the level of safety. Then, in order to solve a problem of fragmentation of control systems and replace different ATP within Europe and improve some other KPT, ERTMS has proven to be a good solution. Classes of TCIS, such as ATP and Driver Advice Systems have a lower importance because their role is significant only for individual KPT.

Regarding the sub criteria - i.e., KPT for sustainable railway (see Fig. 4) - the importance indicates from which aspects classes of TCIS have been studied most commonly. Safety has reached the highest importance, which would mean that classes of TCIS and their subsystems have usually been considered in terms of safety. Although the railways are the safest mode of transport, there are concerns because each fault of the system can cause significant consequences, including fatalities. Consequently, solutions for modification of individual subsystems and comprehensive TCIS are necessary. The second most important point of view, from which TCIS and subsystems were studied, were in regard to the costs, including costs of equipment, installation, maintenance and operation. Since the mentioned cost can be very high, their potential reductions have been frequently considered in the literature. Compared to the previous, themes such as energy consumption, railway capacity, punctuality, and efficiency of train operation emerged as less important. The least importance was shown to be the quality of railway service, interoperability, reliability and availability. 
These findings provide the basis for further research of particular systems in terms of appropriate KPT. The results provide an overview of the trends of research, and primarily the role of ITCS in achievement of sustainable railways. Based on the importance of KPT, the priority area for raising the sustainability of railways should be recognised. Further, the presented results could be used as support in decision making in implementation of a new system such as ERTMS or in upgrading existing TCIS for different railway companies and all kinds of stakeholders in providing sustainable railways.

\section{Conclusions}

In the process of evaluation of the efficiency of any mode of transportation, the most important factor today seems to be its sustainability. Rail transportation has considerable advantages over other modes of transport, because of its relatively low negative impact on the environment and society, and it's very high importance in terms of capacity for the transport of people and cargo. The focus on the further development of sustainable railways is essential for every national economy. A significant contribution in this development can be assigned to modern information and communication technologies (ICT), known also as intelligent transportation systems (ITS), which represent a set of complex systems with many different positive impacts on railway transport. One of the most important among them is a set of Train Control Information Systems (TCIS). The complexity of TCIS may presumed from their complex classification, each class including many subsystems and technologies, one of the results indicated in this paper.

In order to be able to evaluate the importance of an individual class of TCI systems and their subsystems, a detailed literature review was performed and the number of studies (scientific journal papers) that have focused on TCIS and their improvements on railway sustainability was used as a main criteria in AHP evaluation or ranking of these systems. With AHP the highest importance was given to Train Management and Interlocking Systems and their subsystems. The same criteria - the frequency of study - was also used for the evaluation of Key Performance Themes for sustainable railways, also identified during the review. The most important themes were safety and costs of equipment, installation, maintenance and operation.

The results of the research presented in this paper are important for both, scholars for their future research into railway sustainability, and for other railway stakeholders and decision makers, who must select different systems and technologies for implementation in their railway systems with emphasis on increasing performance and sustainability. In order to achieve enhancement in terms of sustainability it is necessary to take into account interactions between classes of TCIS. Therefore, the findings can help in the recognition of relations between some classes of TCIS and KPT and their contributions for the improvement of railways. Moreover, based on the identified KPT appropriate key indicators could be developed which will be used as a measures in monitoring and evaluating classes of TCIS according to sustainable railways.

The research also has some limitations. First of all, the literature review was limited only to the scientific journal papers published in the English language during the period between 2005 and 2016, indexed into Science Direct and Scopus databases, of which the full text is available for free, focused on the TCI systems and subsystems and their improvements in regard to railway sustainability. Second, the search process was realized based on subjectively selected search string(s)/ keywords. Another limitation of the search process presents the fact, that the snowballing process was performed mainly on titles and publication type and date of referenced literature only for those papers that passed these criteria were the abstract and full-text read. Finally, the evaluation of TCIS classes and KPT was conducted through the qualitative judgements of authors. In the future, the research could include valuable technical reports, professional studies, and other papers, and also other ICT and ITS railway systems. Further, our criteria (i.e., number of found references for each system and/or themes) could be upgraded or verified by using the subjective judgments of railway experts. Finally, definitions and lists of individual indicators and measures for each KPT and the means of evaluation of TCIS through these indicators could be performed.

Open Access This article is distributed under the terms of the Creative Commons Attribution 4.0 International License (http:// creativecommons.org/licenses/by/4.0/), which permits unrestricted use, distribution, and reproduction in any medium, provided you give appropriate credit to the original author(s) and the source, provide a link to the Creative Commons license, and indicate if changes were made.

\section{References}

1. Albrecht T, Luipen JV (2006) What role can a driver information system play in railway conflicts? IFAC Proc Vol. 39(12): 251-256

2. Allotta B, Pugi L, Ridolfi A, Malvezzi M, Vettori G, Rindi A (2012) Evaluation of odometry algorithm performances using a railway vehicle dynamic model. Veh Syst Dyn 50(5):699-724

3. Arai H, Manabe K, Sato K (2007) Development of Basic System on ATS-X with Continuous Surveillance Pattern. Quart Rep Railway Tech Res Inst 48(2):89-93

4. Asada T, Roberts C, Koseki T (2013) An algorithm for improved performance of railway condition monitoring equipment: Alternating-current point machine case study. Transp Res C 30:8192

5. Awasthi A, Chauhan SS (2012) A hybrid approach integrating Affinity Diagram, AHP and Fuzzy TOPSIS for sustainable city logistics planning. Appl Math Model 36:573-584 
6. Baldini G, Fovino IN, Masera M, Luise M, Pellegrini V, Bagagali E, Rubino G, Malangone R, Stefano M, Senesi F (2010) An early warning system for detecting GSM-R wireless interference in the high-speed railway infrastructure. Int J Crit Infrastruct Prot 3:140 156

7. Bandara D, Abadie A, Melaragno T, Wijesekara D (2014) Providing Wireless Bandwidth for High-speed Rail Operations. Proc Technol 16:186-191

8. Becheikh N, Landry R, Amara N (2006) Lessons from innovation empirical studies in the manufacturing sector: A systematic review of the literature from 1993-2003. Technovation 26:644-664. doi: 10.1016/j.technovation.2005.06.016

9. Belmonte F, Schon W, Heurley L, Capel R (2011) Interdisciplinary safety analysis of complex socio-technological systems based on the functional resonance accident model: An application to railway traffic supervision. Reliab Eng Syst Saf 96: 237-249

10. Bergman Borges Vieira G, Kliemann Neto FJ, Goncalves Amaral F (2014) Governance, governance models and port performance: a sytematic review. Transp Rev 34(5):645-662

11. Bersani C, Qiu S, Sacile R, Sallak M, Schon W (2015) Rapid, robust, distributed evaluation and control of train scheduling on a single line track. Control Eng Pract 35:12-21

12. Beugin J, Marais J (2012) Simulation-based evaluation of dependability and safety properties of satellite technologies for railway localization. Transp Res C 22:42-57

13. Bosschaart M, Quaglietta E, Janssen B, Goverde RMP (2015) Efficient formalization of railway interlocking data in RailML. Inf Syst 49:126-141

14. Bu B, Yu RF, Tang T (2014) Performance improved methods for communication-based train control systems with random packet drops. IEEE Trans Intell Transp Syst 15(3):1179-1192

15. Carvajal-Carreño W, Cucala AP, Fernández-Cardador A (2014) Optimal design of energy-efficient ATO CBTC driving for metrolines based on NSGA-II with fuzzy parameters. Eng Appl Artif Intell 36:164-177

16. Carvajal-Carreño W, Cucala AP, Fernández-Cardador A (2016) Fuzzy train tracking algorithm for the energy efficient operation of CBTC equipped metro lines. Eng Appl Artif Intell 53:19-31

17. Chen J, Roberts C, Weston P (2006) Neuro-fuzzy fault detection and diagnosis for railway track circuits. IFAC Proc Vol 39(13): 1366-1371

18. Chen J, Roberts C, Weston V (2008) Fault detection and diagnosis for railway track circuits using neuro-fuzzy systems. Control Eng Pract 16:585-596

19. Chen L, Z-y S, Tang T, H-j L (2011) Performance analysis and verification of safety communication protocol in train control system. Comput Stand Interface 33:505-518

20. Chen L, Tang T, Zhao X, Eckehard S (2012) Verification of the safety communication protocol in train control system using colored Petri net. Reliab Eng Syst Saf 100:8-18

21. Chen D, Wang L, Li L (2015) Position computation models for high-speed train based on support vector machine approach. Appl Soft Comput 30:758-766

22. Cheng R, Zhou J, Chen D, Song Y (2016) Model-based verification method for solving the parameter uncertainty in the train control system. Reliab Eng Syst Saf 145:169-182

23. Center for Environmental Excellence (2009) Transportation and sustainability best practices background. Center for Environmental Excellence by AASHTO

24. Chowdhury M (2010) Editorial: 15th intelligent transportation systems world congress. J Intell Trans Syst 14(2):51-53

25. Corman F, D'Ariano A, Pacciarelli D, Pranzo M (2009) Evaluation of green wave policy in real-time railway traffic management. Transp Res C 17:607-616
26. Decimbre A, Ricci S (2011) Railway traffic on high density urban corridors: capacity, signalling and timetable. J Rail Trans Plan Manag 1:59-68

27. Directive 2001/13/EC (2001) Directive 2001/13/EC of the European Parliament and of the Council of 26 February 2001 amending Council Directive 95/18/EC on the licensing of railway undertakings. Off J Eur Union

28. Directive 2004/49/EC (2004) Directive 2004/49/EC of the European Parliament and of the Concil 29 April 2004. Off J Eur Union

29. Directive 2004/50/EC (2004) Directive 2004/50/EC of the European Parliament and of the Council of 29 April 2004. Off J Eur Union

30. Dina AO, Akanni CO, Badejo BA (2016) Evaluation of Railway Level Crossing Attributes on Accident Causation in Lagos, Nigeria. Indones J Geogr 48(2): 108-117

31. Djordjević B, Krmac E (2016) Key performance indicators for measuring the impacts of ITS on transport. Paper presented at the meeting 24th International Syposium on Electronics in transport (ISEP2016), Electrotechnical Association of Slovenia and ITS Slovenia, Ljubljana, Slovenia

32. Domínguez M, Fernández-Cardador A, Cucala AP, Gonsalves T, Fernández A (2014) Multi objective particle swarm optimization algorithm for the design of efficient ATO speed profiles in metrolines. Eng Appl Artif Intell 29:43-53

33. Douglas, A (2007) The case for rail 2007. Rail Safety and Standards Board

34. Douglas H, Roberts C, Hillmansen S, Schmid F (2015) An assessment of available measures to reduce traction energy use in railway networks. Energy Convers Manag 106:1149-1165

35. Durmuș SM, Yıldırım U, Kurșun A, Söylemez TM (2010) Failsafe signalization design for a railway yard: a level crossing case. IFAC Proc Vol 43(12): 337-342

36. Emery D (2014) Towards a versatile European driver advisory system. WIT Trans Built Environ 135:365-374

37. European Commission (2001) White Paper on transport Roadmap to a single European transport area - Towareds a competitive and resource-efficient transport system. Publ Off Eur Union

38. Fan Y, Khattak JA, Shay E (2007) Intelligent Transportation Systems: What do Publications and Patents Tell Us? J Intell Transp Syst 11(2):91-103

39. Fantechi A, Flammini F, Gnesi S (2014) Formal methods for railway control systems. Int J Softw Tools Technol Transfer 16:643646

40. Fatani IFE, Cocheril Y, Nsiala C, Vrigneau B, Berbineau M, Coudoux FX (2012) Robust train-to-wayside video communications in tunnels using H.264 error-resilient video encoding combined with multiple antenna systems. Trans Res Part C 168-180

41. Fauser J, Peleska J (2014) Dependability in open proof software with hardware virtualization-The railway control systems perspective. Sci Comput Program 91:188-215

42. Fernández-Rodríguez A, Fernández-Cardador A, Cucala AP, Domínguez M, Gonsalves T (2015) Design of Robust and Energy-Efficient ATO Speed Profiles of Metropolitan Lines Considering Train Load Variations and Delays. IEEE Trans Intell Transp Syst 16(4):2061-2071

43. Ferrari A, Fantechi A, Magnani G, Grasso D, Tempestini M (2013) The Metrô Rio case study. Sci Comput Program 78:828 842

44. Forsberg R (2016) Conditions affecting safety on the Swedish railway - train drivers'experiences and perceptions. Saf Sci 85: 53-59

45. Franklin F, Nemtanu F, Teixeira PF (2013) Rail infrastructure, ITS and access charges. Res Transp Econ 41:31-42 
46. Fujita H, Arai H, Sato K (2010) Development of new type automatic train protection ATS-Dx with permissible speed profile using on-board database. Quart Rep Railway Tech Res Inst 51(4):189-195

47. Fukuoka H, Iwata K (2006) Performance evaluation of radiobased train control system. Quart Rep Railway Tech Res Inst 47(2):89-94

48. Garcia FP, Pedregal DJ, Roberts C (2010) Time series methods applied to failure prediction and detection. Reliab Eng Syst Saf 95: 698-703

49. Gercek H, Karpak B, Kilincaslan T (2004) A multiple criteria approach for the evaluation of the rail transit networks in Istanbul. Transportation 31(2):203-228

50. Ghazel M (2014) Formalizing a subset of ERTMS/ETCS specifications for verification purposes. Transp Res C 42:60-75

51. Goverde RM, Corman F, D'Ariano A (2013) Railway line capacity consumption of different railway signalling systems under scheduled and disturbed conditions. J Rail Trans Plan Manag 3:78-94

52. Haidong L, Baohua M, Baoshan W, Peng D, Yong D (2011) Optimization of railway section signalling layout based on quasimoving block. J Trans Syst Eng Info Technol 11(4):103-109

53. Harputlugil T, Prins M, Tanju Gultekin A, Ilker Topcu Y (2011) Conceptual framework for potential implementations of multi criteria decision making (MCDM) methods for design quality assessment. Paper presented at the meeting Management and Innovation for a Sustainable Built Environment, MISBE 2011, CIB International Conference, Amsterdam

54. Hartong M, Goel R, Wijesekera D (2011) Positive train control (PTC) failure modes. J King Saud Univ-Sci 23:311-321

55. Hayat FS, Dhahbi SS, Abbas Turki TA, EI Moundi FA (2010) Modeling of interface dialog between train and balise localization by signaling system ERTMS in dysfunction cases. IFAC Proc Vol 43(8): 618-626

56. Hiraguri S (2008) Evaluation of train control method using prediction control. Quart Rep Railway Tech Res Inst 49(3):163-167

57. Hongsheng S, Jing C, Shiming H (2012) Simulation system engineering for train operation based on cellular automaton. Syst Eng Proc 3:13-21

58. Horne D, Findley DJ, Coble DG, Rickabaugh TJ, Martin JB (2016) Evaluation of radar vehicle detection at four quadrant gate rail crossings. J Rail Trans Plan Manag 6:149-162

59. Hu S-R, Li C-S, Lee C-K (2010) Investigation of key factors for accident severity at railroad grade crossings by using a logit model. Saf Sci 48:186-194

60. Iwata K (2013) Method for verifying system requirement specifications based on train control system safety requirements. Quart Rep Railway Tech Res Inst 54(2):91-96

61. Iwata K, Watanabe I (2010) Risk evaluation method for improvement of railway signalling systems. Quart Rep Railway Tech Res Inst 51(4):205-213

62. Iwata K, Hiraguri S, Watanabe I (2009) Evaluation methods for railway signalling systems from the viewpoint of availability. Quart Rep Railway Tech Res Inst 50(3):152-157

63. James P, Moller F, Nguyen HN, Roggenbach M, Schneider S, Treharne H (2014) On modelling and verifying railway interlockings: tracking train lengths. Sci Comput Program 96: 315-336

64. Jeon CM, Amekudzi A (2005) Addressing sustainability in transportation systems: definitions, indicators, and metrics. J Infrastruct Syst 11(1):1-31

65. Kanso K, Moller F, Setzer A (2009) Automated verification of signalling principles in railway interlocking systems. Electron Notes Theor Comput Sci 250:19-31

66. Kawalec P, Rzysko M (2016) Modern methods in railway interlocking algorithms design. Microprocess Microsyst 44:38-46
67. Khan SA, Zafar AN, Ahmad F, Islam S (2014) Extending Petri net to reduce control strategies of railway interlocking system. Appl Math Model 38:413-424

68. Kitano T, Sasaki T, Sugiyama Y (2015) Development of a train control system by using the on-board interlocking. Quart Rep Railway Tech Res Inst 56(1):45-50

69. Kolosz BW, Grant-Muller SM, Djemame K (2012) A macroscopic forecasting framework for estimating socioeconomic and environmental performance of intelligent transport highways. IEEE Trans Intell Trans Syst 15(2)

70. Laapotti V (2016) Comparison of fatalmotor vehicle accidents at passive and active railway level crossings in Finland. IATSS Res 40:1-6

71. Laroche F, Guihery L (2013) European rail traffic management system (ERTMS): supporting competition on the European rail network? Res Transport Bus Manag 6:81-87

72. Laure GS, Kim I, Rakotonirainy A, Haworth NL (2015) Driver's behavioural changes with new intelligent transport system interventions at railway level crossings-A driving simulator study. Accid Anal Prev 81:74-85

73. Laure GS, Rakotonirainy A, Haworth NL, Darvell M (2015) Assessing driver acceptance of intelligent transport systems in the context of railway level crossings. Transp Res F 30:1-13

74. Lee J-H, Hwang J-G, Shin D, Lee K-M, Kim S-U (2009) Development of verification and conformance testing tools for railway signalling communication protocol. Comput Stand Interface 31:362-371

75. Legrand C, Beugin J, Marais J, Conrard B, El-Koursi E-M, Berbineau M (2016) From extended integrity monitoring to the safety evaluation of satellite-based localisation system. Reliab Eng Syst Saf 155:105-114

76. Li S, Yang L, Gao Z (2015) Coordinated cruise control for highspeed train movements based on a multi-agent model. Transp Res C 56:281-292

77. Li K, Yao X, Chen D, Yuan L, Zhou D (2015) HAZOP study on the CTCS-3 onboard system. IEEE Trans Intell Transp Syst 16(1): $162-171$

78. Lin-Hai Z, Jian-Ping W, Yi-Kui R (2012) Fault diagnosis for track circuit using AOK-TFRs and AGA. Control Eng Pract 20:1270 1280

79. Lijie C, Tao T, Xianqiong Z, Schnieder E (2012) Verification of the safety communication protocol in trrain control system using colored Petri net. Reliab Eng Syst Saf 100:8-18

80. Liu J, Wang X, Khattak AJ, Hu J, Cui J, Ma J (2016) How big data serves for freight safety management at highway-rail grade crossings? A spatial approach fused with path analysis. Neurocomputing 181:38-52

81. Lopez I, Aguado M, Jacob E (2014) End-to-End Multipath Technology-Enhancing Availability and Reliability in NextGeneration Packet-Switched Train Signaling Systems. IEEE Vehic Technol Mag 28-35. doi:10.1109/MVT.2013.2295072

82. Luthra S, Kumar Mangla S, Xu L, Diabat A (2016) Using AHP to evaluate barriers in adopting sustainable consumption and production initiatives in a supply chain. International Journal of Production Economics. Retrieved from http://dx.doi.org/10. 1016/j.ijpe.2016.04.001

83. Mandic D, Jovanovic P, Bugarinovic M (2014) Two-phase model for multi-criteria project ranking: Serbian railways case study. Transp Policy 36:88-104

84. Manz H, Becker U, Schnieder E (2016) Enabling certification of satellite based localization in railways by combination of redundant sensors and map matching. IFAC-PapersOnLine 493:178-183

85. Marais J, Beugin J (2012) Evaluation method of GNSS-based positioning functions for safety applications in operational conditions. Proc-Soc Behav Sci 48:806-815 
86. Mardani A, Zavadskas EK, Khalifah Z, Jusoh A, Nor KMD (2016) Multiple criteria decision-making techniques in transportation systems: a systematic review of the state of nthe art literature. Transport 31(3):359-385

87. Márquez FP, Pedregal DJ (2006) An algorithm for detecting faults in railway point mechanisms. IFAC Proc Vol 39(13): 1360-1365

88. Marquez FPG, Schmid F (2007) A digital filter-based approach to the remote condition monitoring of railway turnouts. Reliab Eng Syst Saf 92:830-840

89. Marquez FPG, Tercero DJP, Schmid F (2007) Unobserved Component models applied to the assessment of wear in railway points: a case study. Eur J Oper Res 176:1703-1712

90. Marquez FPG, Weston P, Roberts C (2007) Failure analysis and diagnostics for railway trackside equipment. Eng Fail Anal 14: $1411-1426$

91. Marquez FP, Lewis RW, Tobias AM, Roberts C (2008) Life cycle costs for railway condition monitoring. Transp Res E 44:11751187

92. Marquez FP, Pedregal DJ, Roberts C (2015) New methods for the condition monitoring of level crossings. Int J Syst Sci 46(5):878884

93. Mekki A, Ghazel M, Toguyeni A (2012) Validation of a new functional design of automatic protection systems at level crossings with model-checking techniques. IEEE Trans Intell Transp Syst 13(2):714-723

94. Millegan H, Yan X, Richards S, Han L (2009) Evaluation of effectiveness of stop-sign treatment at highway-railroad grade crossings. J Transport Safety Secur 1:46-60

95. Miyaguchi N, Uchiyama D, Inada I, Baba Y, Hiura N (2014) The radio-based train control system ATACS. WIT Trans Built Environ 155:175-183

96. Miyoshi M, Takeba T, Miyatake M (2012) Development of an energy efficient train traffic control system for saving electricity. WIT Trans Built Environ 127:499-510

97. Molodova M, Oregui M, Núñez A, Li Z, Dollevoet R (2016) Health condition monitoring of insulated joints based on axle box acceleration measurements. Eng Struct 123:225-235

98. Mazzarello M, Ottaviani E (2007) A traffic management system for real-time traffic optimisation in railways. Transp Res B 41: 246-274

99. Nakamura H (2016) How to deal with revolutions in train control systems. Engineering 2:380-386

100. Network Rail (2013) Sustainable Development Strategy: Our vision and strategy - A railway fit for the future 2013-2024. Network Rail. Retrieved from http://www.networkrail.co.uk/ browsedocuments/strateg.../sustainable development strategy.pdf $-93 \mathrm{k}-20$

101. Oh J, Washington SP, Nam D (2006) Accident prediction model for railway-highway interfaces. Accid Anal Prev 38:346-356

102. Öörni R (2013) Reliability of an in-vehicle warning system for railway level crossings - a user-oriented analysis. IET Intell Transp Syst 8(1):9-20. doi:10.1049/iet-its.2012.0129

103. Ortmeier F, Schellhorn G (2007) Formal fault tree analysis - practical experiences. Electron Notes Theor Comput Sci 185:139-151

104. Oukhellou L, Debiolles A, Denoeux T, Aknin P (2010) Fault diagnosis in railway track circuits using Dempster-Shafer clasiffier fusion. Eng Appl Artif Intell 23:117-128

105. Panou K, Tzieropoulos P, Emery D (2013) Railway driver advice systems: evaluation of methods, tools and systems. J Rail Transport Plan Manag 3:150-162

106. Patra AP, Kumar U (2010) Availability analysis of railway track circuits. Proc Inst Mech Eng Part F: Rail Rapid Transit 224:169 177

107. Pattanaik LN, Yadav G (2015) Decision support model for automated railway level crossing system using fuzzy logic control. Proc Comput Sci 48:73-76
108. Petersen K, Vakkalanka S, Kuzniarz L (2015) Guidelines for conducting systematic mapping studies in software engineering: an update. Info Softw Technol 64

109. Podvezko V (2009) Application of AHP technique. J Bus Econ Manag 10(2):181-189

110. Qiu S, Sallak M, Cherfi-Boulanger Z (2014) Availability assessment of railway signalling systems with uncertainty analysis using Statecharts. Simul Model Pract Theory 47:1-18

111. Quaglietta E (2014) A simulation-based approach for the optimal design of signalling block layout in railway networks. Simul Model Pract Theory 46:4-24

112. Rajkumar RI, Sankaranarayanan P, Sundari G (2015) An approach to implementation of intelligent signaling for automatic blocking system in railway sectors using mobile agents. Proc Comput Sci 46:337-345

113. Read GJ, Salmon PM, Lenne MG, Stanton NA (2016) Walking the line: understanding pedestrian behaviour and risk at rail level crossings with cognitive work analysis. Appl Ergon 53:209-227

114. Rispoli F, Neri A, Senesi F (2014) Innovative train control systems based on ERTMS and satellite-public TLC networks. WIT Trans Built Environ 135:51-61

115. Rodríguez-Morcillo C, Alexandres S, Muñoz JD (2009) Broadband system to increase bitrate in train communication networks. Comput Stand Interface 31:261-271

116. Rongwu C, Tao Y, Bisrat BR (2014) A genetic algorithm based train speed regulation optimization. WIT Trans Built Environ 135: 791-802

117. Rose JA, Bearman C (2012) Making effective use of task analysis to identify human factors issues in new rail technology. Appl Ergon 43:614-624

118. Saaty TL (1977) A scaling method for priorities in hierarhical structures. J Math Psychol 15:234-281

119. Saaty TL (1980) The Analytic Hierarchy Process. McGraw-Hill Book Company, New York

120. Saaty TL (2004) Decision making - the analytic hierarchy and network processes (AHP/ANP). J Syst Sci Syst Eng 13(1):1-35

121. Saaty TL (2008) Decision making with the analytic hierarchy process. Int J Service Sci 1(1):83-98

122. Saccomanno FF, Park PY-J, Fu L (2007) Estimating countermeasure effects for reducing collisions at highway-railway grade crossings. Accid Anal Prev 39:406-416

123. Salmon PM, Lenné MG, Read GJ, Mulvihill CM, Cornelissen M, Young KL, Stevens N (2015) Beyond the crossing: a cognitive work analysis of rail level crossing systems. Proc Manuf 3:29212928

124. Salmon PM, Lenné MG, Read GJ, Mulvihill CM, Cornelissen M, Walker GH, Young KL, Stevens N, Stanton NA (2016) More than meets the eye: Using cognitive work analysis to identify design requirements for future rail level crossing systems. Appl Ergon 53: $312-322$

125. Senesi F (2012) Satellite application for train control systems: the test site in Sardinia. J Rail Trans Plan Manag 2:73-78

126. ShangGuan W, Yan X-H, Cai B-G, Wang J (2015) Multiobjective optimization for train speed trajectory in CTCS high-speed railway with hybrid evolutionary algorithm. IEEE Trans Intell Transp Syst 16(4):2215-2225

127. Shara S, Bagavathi PS, Ananthanarayanan V (2016) An automated system to mitigate loss of life at unmanned level crossings. Proc Comput Sci 92:404-409

128. Siciliano G, Musolino D (2016) Economic evaluation of a technological leap in the sector of train control and signalling: the case of German regional lines. Trans Res Proc 14:430-437

129. Silmon JA, Roberts C (2010) Improving railway switch system reliability with innovative condition monitoring algorithms. Proc Inst Mech Eng Part F: Rail Rapid Transit 224:293-302 
130. Silmon J, Roberts C (2010) Using functional analysis to determine the requirements for changes to critical systems: railway level crossing case study. Reliab Eng Syst Saf 95:216-225

131. Smith P, Majumdar A, Ochieng WY (2012) An overview of lessons learnt form ERTMS implementation in European railways. J Rail Trans Plan Manag 2:79-87

132. Srdjevic B, Srdjevic Z, Blagojevic B, Suvocarev K (2013) A twophase algorithm for consensus building in AHP-group decision making. Appl Math Model 37:6670-6682

133. Stadlmann B (2008) Basic train control system for regional branch lines - field test report. WIT Trans Built Environ 103:253-262. doi:10.2495/CR080261

134. Sun W, Yu FR, Tang T, Bu B (2016) Energy-efficient communication-based train control systems with packet delay and loss. IEEE Trans Intell Transp Syst 17(2):452-468

135. Tey L-S, Ferreira L, Wallace A (2011) Measuring driver responses at railway level crossings. Accid Anal Prev 43:2134-2141

136. Tey L-S, Wallis G, Cloete S, Ferreira L (2013) Modelling driver behaviour towards innovative warning devices at railway level crossings. Accid Anal Prev 51:104-111

137. Tey L-S, Zhu S, Ferreira L, Wallis G (2014) Microsimulation modelling of driver behaviour towards alternative alternativewarning devices at railway level crossings. Accid Anal Prev 71:177-182

138. Tschirner S, Sandblad B, Andersson AW (2014) Solutions to the problem of inconsistent plans in railway traffic operation. J Rail Trans Plan Manag 4:87-97

139. Vaidya OS, Kumar S (2006) Analytic hierarchy process: an overview of applications. Eur J Oper Res 169:1-29

140. Veith A (2012) Railways and sustainable development: a global perspective. International Union of Railways, Paris

141. Verma A, Pattanaik KK (2014) Mobile agent based train control system for mitigating meet conflict at turnout. Proc Comput Sci 1(2317-324):32

142. Wang Y, Schutter BD, van den Boom TJ, Ning B (2014) Optimal trajectory planning for trains under fixed and moving signaling systems using mixed integer linear programming. Control Eng Pract 22:44-56

143. Wang J, Wang J, Roberts C, Chen L (2015) Parallel monitoring for the next generation of train control systems. IEEE Trans Intell Transp Syst 16(1):330-338

144. Wang J, Li Y, Zhang Y (2016) Research on parallel control mechanism and its implementation in ATP. IEEE Trans Intell Transp Syst 17(6):1652-1662

145. Wang J, Roberts C, Chen L, Zhang Y (2016) An approach to eliminate train route setting errors through application of parallel monitoring. Saf Sci 86:228-237

146. Wang P, Goverde RM (2016) Multiple-phase train trajectory optimization with signalling and operational constraints. Transp Res C 69:255-275

147. Washington S, Oh J (2006) Bayesian methodology incorporating expert judgment for ranking countermeasures effectiveness under uncertainty: example applied to at grade railroad crossings in Korea. Accid Anal Prev 38:234-247

148. C-1 W, Lai C-c, S-y L, Chung WH, Ho TK, H-y T, Lee KY (2010) A fiber bragg grating sensor system for train axle counting. IEEE Sensors J 10(12):1905-1912

149. Wullems C (2011) Towards the adoption of low-cost rail level crossing warning devices in regional areas of Australia: A review of current technologies and reliability issues. Saf Sci 49:1059 1073

150. Xiangxian C, Yulin H, Hai H (2011) A component-based topology model for railway interlocking systems. Math Comput Simul 81: $1892-1900$

151. Xun J, Ning B, Li KP (2008) Multi-objective optimization method for the ATO system using cellular automata. WIT Trans Built Environ 103:173-182

152. Xun J, Ning B, K-p L, W-b Z (2013) The impact of end-to-end communication delay on railway traffic flow using cellular automata model. Transp Res C 35:127-140

153. Yan X, Richards S, Su X (2010) Using hierarchical tree-based regression model to predict train-vehicle crashes at passive highway-rail grade crossings. Accid Anal Prev 42:64-74

154. Yang K, Duan Z, Tian C (2014) Modeling and verification of RBC handover protocol. Electron Notes Theor Comput Sci 309:51-62

155. Yun B, Tinkin H, Baohua M (2011) Train control to reduce delays upon service disturbances at railway junctions. J Transport Syst Engand Info Technol 11(5):114-122

156. Zattoni E (2006) Detection of incipient failures by using H2-norm criterion: application to railway switching points. Control Eng Pract 14:885-895

157. Zeng J, Qian Y, Li W, Guang X, Wang M (2014) A study on the effects of redundant time on the operation of different speed-grade trains in passenger railway line traffic system by using cellular automata model. Adv Mech Eng 9

158. Zhao L, Cai B, Xu J, Ran Y (2014) Study of the track-train continuous information transmission process in a high-speed railway. IEEE Trans Intell Transp Syst 15(1):112-121

159. Zhao Y, Ioannou P (2015) Positive train control with dynamic headway based on an active communication system. IEEE Trans Intell Transp Syst 16(6):3095-3103

160. Zhu L, Yu FR, Ning B, Tang T (2012) Cross-layer handoff design in MIMO-enabled WLANs for communication-based train control (CBTC) systems. IEEE J Select Areas Comm 30(4):719-728

161. Zhu L, Yu FR, Ning B, Tang T (2014) Communication-based train control (CBTC) systems with cooperative relaying: design and performance analysis. IEEE Trans Vechicular Technol 63(5): 2162-2172

162. Zhu L, Yu FR, Ning B, Tang T (2014) Design and performance enhancements in communication-based train control systems with coordinated multipoint transmission and reception. IEEE Trans Intell Transp Syst 15(3):1258-1272

163. Zimmermann A, Hommel G (2005) Towards modeling and evaluation of ETCS real-time communication and operation. J Syst Softw 77:47-54 